\title{
The influence of alloying on the phase formation sequence of ultra-thin nickel silicide films and on the inheritance of texture
}

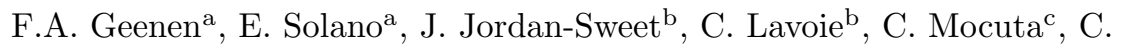 \\ Detavernier $^{\mathrm{a}}$ \\ ${ }^{a}$ Department of Solid-State Sciences, Ghent University, 9000 Gent, Belgium \\ ${ }^{b} I B M$ T.J. Watson Research Center, Yorktown Heights, NY, USA \\ ${ }^{c}$ Synchrotron SOLEIL, L'Orme des Merisiers, Saint Aubin BP48, 91192 Gif-sur-Yvette, \\ France
}

\begin{abstract}
The controlled formation of silicide materials is an ongoing challenge to facilitate the electrical contact of Si-based transistors. Due to the ongoing miniaturisation of the transistor, the silicide is trending to ever-thinner thickness's. The corresponding increase in surface-to-volume ratio emphasises the importance of low-energetic interfaces. Intriguingly, the thickness reduction of nickel silicides results in an abrupt change in phase sequence.

This paper investigates the sequence of the silicides phases, and their preferential orientation with respect to the $\mathrm{Si}(001)$ substrate, for both 'thin' (i.e. $9 \mathrm{~nm}$ ) and 'ultra-thin' (i.e. $3 \mathrm{~nm}$ ) Ni films. Furthermore, as the addition of ternary elements is often considered in order to tailor the silicides' properties, additives of $\mathrm{Al}, \mathrm{Co}$ and $\mathrm{Pt}$ are also included in this study.

Our results show that the first silicide formed is epitaxial $\theta-\mathrm{Ni}_{2} \mathrm{Si}$, regardless of initial thickness or alloyed composition. The transformations towards subsequent silicides are changed through the additive elements, which can be understood through solubility arguments and classical nucleation theory.

The crystalline alignment of the formed silicides with the substrate significantly differs through alloying. The observed textures of sequential silicides
\end{abstract}

Email address: filip.geenen@ugent.be (F.A. Geenen) 
could be linked through texture inheritance. Our study illustrates that the nucleation of a new phase drive to reduce the interfacial energy at the silicidesubstrate interface as well as at the interface with the silicide which is being consumed for these sub-10nm thin films.

Keywords: nickel silicide, epitaxy, axiotaxy, texture

\section{Introduction}

The nickel silicides have been studied thoroughly in the past due to the beneficial properties of NiSi (e.g. low sheet resistance, low Schottky Barrier Height, low formation temperature) for usage as contact material in Si-based 5 transistor devices [1, 2, 3]. The phase formation process typically involves the annealing of an as-deposited Ni film on top of a Si substrate, resulting in the sequential formation of $\delta-\mathrm{Ni}_{2} \mathrm{Si}, \theta-\mathrm{Ni}_{2} \mathrm{Si}, \mathrm{NiSi}$ and $\mathrm{NiSi}_{2}$ [4, 5, 6, 7]. Recent investigation of this 'regular' phase sequence for relatively thick Ni films (i.e. for an as-deposited Ni thickness of e.g. 6 - $30 \mathrm{~nm}$ ) showed that the solid-phase reaction $(\mathrm{SPR})$ includes a complex balance in thermodynamic parameters. For example, the phase sequence is known to include $\theta-\mathrm{Ni}_{2} \mathrm{Si}$ [5, 6, 7, 8, a transient phase which is metastable. In addition to the observation of $\theta-\mathrm{Ni}_{2} \mathrm{Si}$, Gaudet et al. observes an unidentified epitaxial phase was also observed in the SPR at their lowest investigated temperature, i.e. $290^{\circ} \mathrm{C}$.

Due to the constant urge for miniaturisation in micro-electronic applications, the silicide contacts are trending to ever-thinner films. Surprisingly, for as-deposited and pure Ni films of only a few nanometres thick, no NiSi is formed [9, 10, 11]. It was already observed by Tung et al. in the early 80's that the phase sequence is significantly different when the as-deposited Ni layer is thinner than ca. $5 \mathrm{~nm}\left[12,13\right.$. In this 'ultrathin' SPR, the $\delta-\mathrm{Ni}_{2} \mathrm{Si}$ and NiSi phases are not formed and instead, $\mathrm{NiSi}_{2}$ is already present at temperatures as low as $400^{\circ} \mathrm{C}$, at least $300^{\circ} \mathrm{C}$ earlier than in the 'regular' SPR. Intriguingly, an epitaxial, intermediate phase - with similar diffraction signature as observed in the 'regular' phase formation by Gaudet et al. [6] - was observed during this 
ultrathin SPR, prior to the formation of low-temperature $\mathrm{NiSi}_{2}$. The observation that both silicide formation regimes first form the same epitaxial phase, indicates that the origin of the shift from the regular regime to the ultra-thin regime should lie in the formation of subsequent phases. Films with these low thicknesses will receive a high energetic drive to optimise the interface alignso ment with the substrate. Therefore, the correlation between the silicide phase sequence and the silicides' preferential orientation is of crucial importance for these sub-10 $\mathrm{nm}$ thin films.

An intriguing question is how both the regular, as well as in the ultrathin film regimes, is affected through the addition of ternary elements. Indeed, silicides are often tailored through the addition of alloying elements to the as-deposited metal film, in order to alter the final properties of the formed phases 14, 15, 16, 4. As one of the more contemporary examples, Pt-incorporation in NiSi films is known to improve the films' morphological stability, as well as to alter the preferential orientation to the Si substrate [16, 17]. Moreover, it is also reported 40 that Pt can influence the thermodynamic stability of the intermediate silicide such as $\delta-\mathrm{Ni}_{2} \mathrm{Si}[18,19,8]$. However, the influence of ternary elements on the solid-phase formation during the sequential growth of silicides in this sub-10 nm thickness region has not been studied in a systematic way. As we will show, these silicides are often epitaxially aligned with the substrate which renders 45 them challenging to investigate by conventional, lab-based, Bragg-Brentano Xray diffraction $(\mathrm{XRD})$.

This paper investigates the phase formation in both the 'thin' (i.e. with an as-deposited Ni thickness $=9 \mathrm{~nm}$ ) and in the 'ultrathin' (i.e. Ni thickness $=3 \mathrm{~nm}) \mathrm{SPR}$ regime and how this is influenced by alloying with Pt, Co and

50 Al. These alloying elements were selected because of their different solubility in the various nickel silicide phases. Through complementary synchrotron-based XRD measurements, we obtain a comprehensive understanding of the silicide formation, and preferential orientation of the resulting phases to the $\mathrm{Si}(001)$ substrate, as a function of film thickness, alloying elements and annealing tem${ }_{55}$ perature. This enables a discussion how the solid-phase reaction and preferential 
orientation are correlated in these sub-10 nm films.

\section{Experimental methods}

Thin Ni films of both 3 and $9 \mathrm{~nm}$ thick were deposited through physical vapour deposition (PVD) on top of single crystalline Si substrates with (001) orientation. Samples for in situ sheet resistance measurements were sputtered on silicon-on-insulator (SOI) substrates with identical orientation and a top $\mathrm{Si}$ thickness of $100 \mathrm{~nm}$. Prior to the deposition, these wafers received a standard chemical cleaning, following the guidelines of the Radio Corporation of America (RCA), ending with a 20 s dip in $3 \%$ HF solution.

After reaching a base pressure of $6 \times 10^{-7}$ mbar, the deposition chamber was filled with Ar up to $5 \times 10^{-3}$ mbar. The deposition of $\mathrm{Ni}$ was performed at a relatively low sputter rate of $1.3 \mathrm{~nm} / \mathrm{min}$, as determined through ex situ X-ray reflectivity (XRR) measurements. The samples were optionally alloyed with an estimated concentration of 10 at.\% of $\mathrm{Al}$, Co or Pt through simultaneous co70 sputtering with separate sputter targets, after careful calibration of the $\mathrm{Al}$, Co and $\mathrm{Pt}$ sputter rates on the basis of XRR. We note that the alloying species were added in addition to the initial Ni content. As Co and Pt are known to replace $\mathrm{Ni}$ atoms during silicide formation, the addition of these alloying elements render an effective increase in the metal supply to form $\mathrm{Ni}_{x} \mathrm{M}_{y} \mathrm{Si}_{z}$ (M

$75=\mathrm{Co}, \mathrm{Pt})$ compounds. Other papers therefore prefer to keep the metal supply constant by reducing the $\mathrm{Ni}$ content when adding a ternary alloy, but such an approach is not easily translated to $\mathrm{Al}$ alloying, which is known to replace the $\mathrm{Si}$ atoms during silicide formation. For conciseness, these samples will be referred to as $\mathrm{Ni}(\mathrm{Al}), \mathrm{Ni}(\mathrm{Co})$ and $\mathrm{Ni}(\mathrm{Pt})$.

The samples were then annealed in a dedicated in situ X-ray diffraction (XRD) set-up at the X20C-beamline of the NSLS synchrotron (Brookhaven, USA). The synchrotron provides adequate X-ray brightness to investigate these ultra-thin samples. The solid-phase reaction between the film and the substrate was monitored during an anneal at a rate of $1{ }^{\circ} \mathrm{C} / \mathrm{sec}$ in a $\mathrm{He}\left(5 \% \mathrm{H}_{2}\right)$ ambient, 
as these samples are otherwise prone to oxidation during the annealing process. The X-rays, with a wavelength of $\lambda=0.180 \mathrm{~nm}$ (i.e. an energy of $6.88 \mathrm{keV}$ ) diffract on the sample in a fixed geometry, therefore only monitoring diffraction signal originating from planes nearly-parallel to the sample's surface. The diffracted intensities were monitored using a custom-build linear detector with

90 a total angular acceptance of $14^{\circ}$ in $2 \theta$. These diffractograms are plotted as a function of temperature and diffraction angle using a grayscale map for the recorded intensity values, where black indicates the highest intensity. A similar annealing set-up was used for in situ sheet resistance measurements during temperature treatment through a four-point probe approach with identical annealing conditions. The measured resistance of the samples were at least one order of magnitude lower compared than the in situ resistance of bare SOI substrates at each temperature. The set-up does not guarantee an identical probe geometry between separate measurements, and as such the measured resistances will be plotted on a relative scale, instead of an absolute scale, as a function of temperature.

As-deposited samples were alternatively quenched from specific temperatures for ex situ pole-figure measurements for crystal phase identification and characterisation of the preferential orientation, also known as crystalline texture. A total of 100 samples were measured in order to obtain a quasi-continuous dataset as a function of quench temperature. These $e x$ situ measurements were performed at the DiffAbs beamline of the SOLEIL synchrotron (Gif-sur-Yvette, France) [20. The incidence X-ray beam is monochromatized using a doublecrystal monochromator to a wavelength of $\lambda=1.55 \mathrm{~nm}$ (i.e. an energy of $8 \mathrm{keV}$ ). A 6-circles diffractometer in kappa geometry was used together with a hybrid pixel area detector $(\mathrm{XPAD}$ detector of $240 \times 560$ pixels, with a pixel size of 130 by $130 \mu \mathrm{m})[21,22,23,24]$. The long side of the detector was mounted in the $2 \theta$ direction, resulting in an angular acceptance determined to be $32^{\circ}$, and around $13^{\circ}$ in the perpendicular direction. The area detector acquired a snapshot every $100 \mathrm{~ms}$ during a continuous in-plane rotation of the samples' azimuth ${ }_{115}$ (denoted as the $\phi$ angle), rotating at a speed of $8^{\circ} \mathrm{s}^{-1}$ and covering $110^{\circ}$ in $\phi$. 
The sample was then rotated in the elevation angle $\chi$ in steps of $5^{\circ}$ from 0 to $85^{\circ}$, rendering significant overlap between two sequential $\chi$ steps. This set-up enables the measurement of a set of pole figures within $4.5 \mathrm{~min}$. Every sample was measured at least three times without re-aligning the sample, in order to obtain adequate diffraction statistics for these sub-10 nm thin films.

The raw data were re-calculated to angular $(\chi, \phi$ and $2 \theta)$ space and the resulting datasets are presented in this paper in polar coordinates with an equalarea projection and a logarithmic-intensity gray-scale with black indicating the highest intensities. The acquired data were symmetrized to a full $360^{\circ} \phi$ coverage, exploiting the four-fold symmetry of the $\mathrm{Si}(001)$ substrate. These pole figures were analysed using a home-developed software package, GUSTAV [25], in order to determine the preferential orientations of the silicides.

\section{Results}

We report on the SPR between the (un)alloyed Ni films with the Si substrate for two different Ni thicknesses: 3 and $9 \mathrm{~nm}$. As mentioned in the previous paragraph, in situ XRD measurements allow continuous phase identification as a function of temperature, on the condition that the diffracting planes are oriented (nearly) parallel to the sample's surface. Epitaxial phases, which do not necessarily fulfil this condition, are alternatively observed through the ex situ pole figures. The latter measurements will also be used to assess the preferential orientation of the silicide grains with respect to the $\mathrm{Si}(001)$ substrate. These orientations will be expressed in terms of lattice planes, and table 1 provides an overview of the unit cells of the occurring nickel silicide phases.

\section{$9 \mathrm{~nm}$ Ni films}

The in situ XRD measurement of an unalloyed, $9 \mathrm{~nm} \mathrm{Ni}$ film is displayed in figure 1 1a. The SPR shows the transformation of the initial Ni diffraction peak at room temperature, into the $\delta-\mathrm{Ni}_{2} \mathrm{Si}$ around $230^{\circ} \mathrm{C}$ by the observation of the $\delta-\mathrm{Ni}_{2} \mathrm{Si}(301)$ plane at $2 \theta=53.6^{\circ}$. The peak at $2 \theta=56.4^{\circ}$, observed in a small 

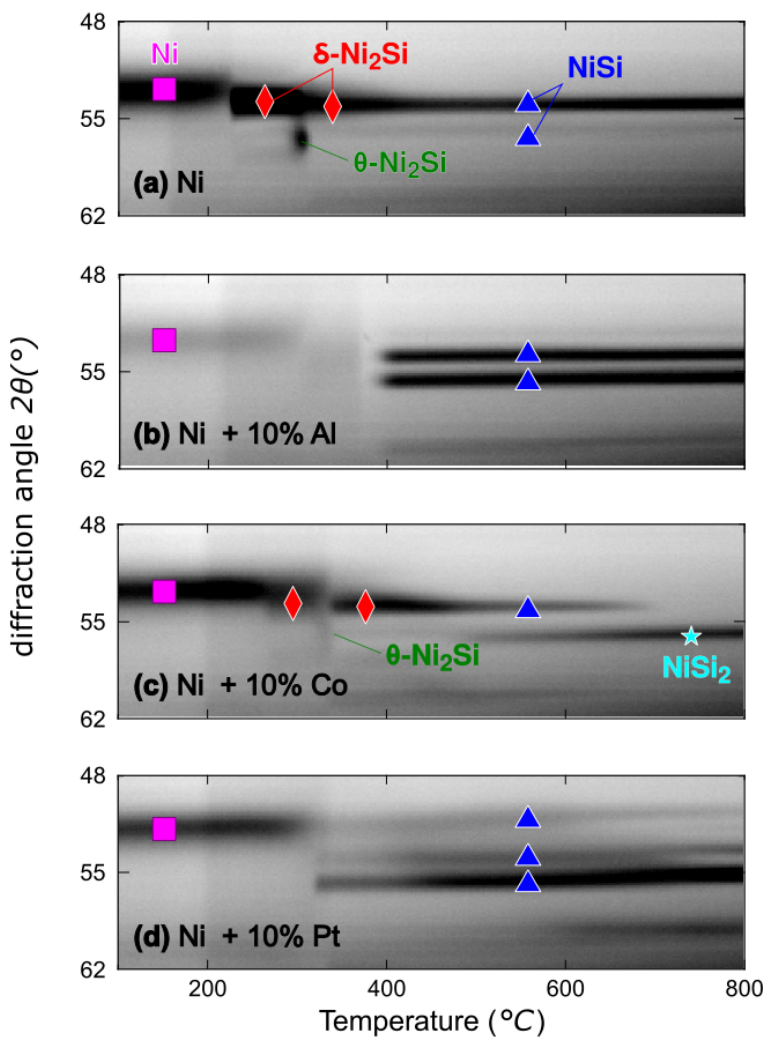

(e) Pole figure quenches

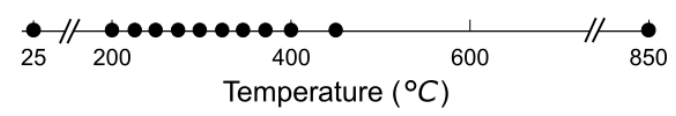

Figure 1: In situ XRD measurements of $9 \mathrm{~nm}$ thick Ni films: unalloyed (a), and alloyed with 10 at.\% $\mathrm{Al}$ (b), Co (c) and Pt (d). These measurements allow to determine the important temperature regions where quenches were made for further ex situ investigation (e), in addition to a measurement at room temperature. 
Table 1: Overview of the binary nickel-based phases observed in this paper.

\begin{tabular}{cccccc}
\hline Phase & Lattice & $a(\AA)$ & $b(\AA)$ & $c(\AA)$ & JCPDS No. \\
\hline $\mathrm{Ni}$ & FCC & 3.524 & - & - & $00-004-0850$ \\
$\delta-\mathrm{Ni}_{2} \mathrm{Si}$ & Orth. & 7.066 & 5.008 & 3.732 & $00-048-1339$ \\
$\theta-\mathrm{Ni}_{2} \mathrm{Si}$ & Hex. & 3.805 & - & 4.890 & $01-073-2093$ \\
$\mathrm{NiSi}$ & Orth. & 5.233 & 3.258 & 5.659 & $00-038-0844$ \\
$\mathrm{NiSi}_{2}$ & FCC & 5.406 & - & - & $03-065-2974$ \\
\hline
\end{tabular}

temperature window of ca. $20^{\circ} \mathrm{C}$ around $300^{\circ} \mathrm{C}$ was discussed in a study by 145 Gaudet et al. [6], and is related to a fiber-textured $\theta-\mathrm{Ni}_{2} \mathrm{Si}$. This $\theta-\mathrm{Ni}_{2} \mathrm{Si}$ phase is then consumed, after which $\delta-\mathrm{Ni}_{2} \mathrm{Si}$ and $\mathrm{NiSi}$ are present. Around $450{ }^{\circ} \mathrm{C}$, $\delta-\mathrm{Ni}_{2} \mathrm{Si}$ is also consumed leaving $\mathrm{NiSi}$ as the only observed phase during the rest of the in situ annealing experiment.

Similar measurements on $\mathrm{Ni}$ samples which are alloyed with 10 at.\% Al, Co and Pt (Fig. 1 b,c and d) show clear differences with the above observations. (i) The as-deposited $\mathrm{Ni}(\mathrm{Al})$ layer diffracts with much lower intensity, which can be explained by a lower crystalline-order of the as-deposited layer due to the incorporation of $\mathrm{Al}$ in the $\mathrm{Ni}$ lattice through the co-sputtering of both materials. However, the Ni-diffraction peak at $2 \theta=53.0^{\circ}$ is still observable and is consumed around $300^{\circ} \mathrm{C}$. No clear silicide phase can be identified immediately thereafter. Instead, a broad background is observed, which diminishes for a small temperature window of $20^{\circ} \mathrm{C}$ just prior to the formation of NiSi. The latter phase is then the only phase remaining throughout the annealing experiment. Comparing the relative diffracted intensities of the NiSi $(112)$ peak $\left(2 \theta=54.0^{\circ}\right)$ to the $(202 / 211)$ peak $\left(2 \theta=55.8^{\circ}\right)$ already hints that the texture of this phase is different from the NiSi texture formed from the pure Ni film. No intermediate phases such as $\delta-\mathrm{Ni}_{2} \mathrm{Si}$ or $\theta-\mathrm{Ni}_{2} \mathrm{Si}$ are observed via in situ XRD during the annealing process. (ii) The annealing of a $\mathrm{Ni}(\mathrm{Co})$ layer is comparable to the pure $\mathrm{Ni}$ reference measurement up to $500^{\circ} \mathrm{C}$, with the similar observation of $\delta-\mathrm{Ni}_{2} \mathrm{Si}$ and $\theta-\mathrm{Ni}_{2} \mathrm{Si}$. At higher temperatures, the formation of $\mathrm{NiSi}_{2}$ is observed as seen through the occurrence of its diffraction peak at $2 \theta=56.0^{\circ}$ and $33.5^{\circ}$ (the latter 
visible through measurements at a different $2 \theta$ diffraction window), far earlier than for unalloyed $\mathrm{Ni}$, where it would only form above $850^{\circ} \mathrm{C}$. (iii) Finally, the in situ XRD of $\mathrm{Ni}(\mathrm{Pt})$ does not contain clear diffraction of intermediate $\mathrm{Ni}_{2} \mathrm{Si}$ phases. Furthermore, similar to the $\mathrm{Ni}(\mathrm{Al})$ sample, there is a significant difference in observed intensity of the NiSi peaks, where now the most intense peak is originating from the $(202) /(211)$ planes $\left(2 \theta=55.8^{\circ}\right)$, again indicating a significant change in preferential orientation.

The in situ XRD measurements indicate that most of the formed phases are observed between 200 and $400^{\circ} \mathrm{C}$. Therefore, ex situ pole figures are measured for samples quenched every $25^{\circ} \mathrm{C}$ in this temperature window, in addition to an as-deposited sample, and quenched samples at 450 and $850{ }^{\circ} \mathrm{C}$ (Fig. 11). For each of these 48 samples, sets of ex situ pole figures were acquired using an area detector, resulting in one pole figure for every value of $2 \theta$ in between 30 and $62^{\circ}$ in a quasi-continuous fashion, due to the 540 pixels along the $2 \theta$ direction. A selection of the measured pole-figure data is shown in figure 2, which contains the integrated diffracted intensities around $2 \theta=45.5^{\circ} \pm 0.4^{\circ}(d=1.98-2.01 \AA$, corresponding to $2 \theta=53.6^{\circ} \pm 0.5^{\circ}$ for the X-ray wavelength used during the in situ XRD measurements). This broad $2 \theta$ window includes diffraction intensities from the $\mathrm{Ni}(111), \delta-\mathrm{Ni}_{2} \mathrm{Si}(301 / 121), \theta-\mathrm{Ni}_{2} \mathrm{Si}(102 / 110)$ and $\mathrm{NiSi}(112)$ planes and serves as an overall illustration of all observed phases. $\mathrm{Si}(220)$ diffraction is also measured, and the position of these epitaxial spots are indicated on the pole figures (e.g. Fig. 2b-i). Other pole figures from the complete set of pole figures (of which a selection will be discussed further) were used to corroborate the phase identification and their texture during the analysis.

In the following overview of our results concerning the $9 \mathrm{~nm}$ Ni films, we first discuss the texture of every occurring phase, as observed for the four differentlyalloyed samples. Thereafter, the change in diffracted intensities of those phases is addressed as a function of temperature, which allows to interpret the rate 195 of formation and consumption of these phases and compare these with in situ XRD measurements. 
(a) $\mathrm{Ni}$
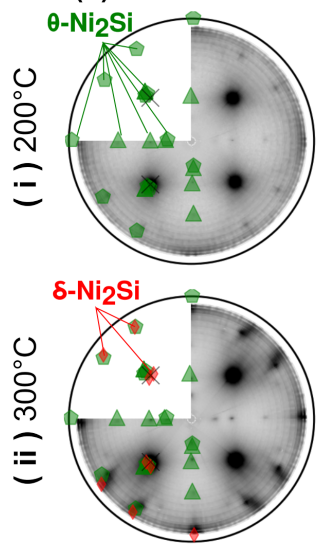

(b) $\mathrm{Ni}+10 \% \mathrm{Al}$

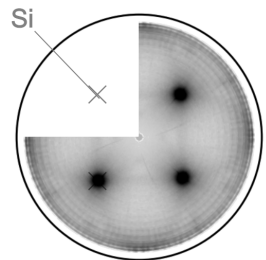

(c) $\mathrm{Ni}+10 \% \mathrm{Co}$

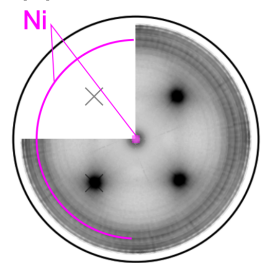

(d) $\mathrm{Ni}+10 \% \mathrm{Pt}$
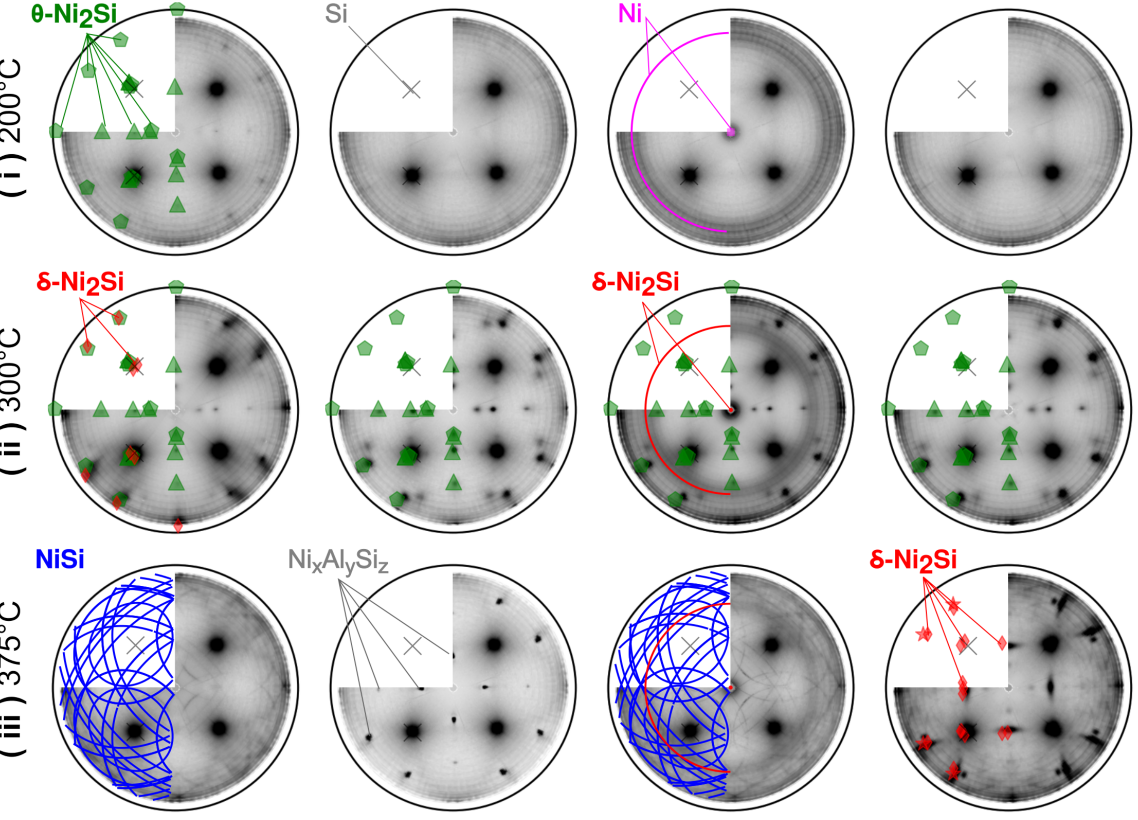

$\mathrm{Ni}_{x} \mathrm{Al}_{y} \mathrm{Si}_{z}$
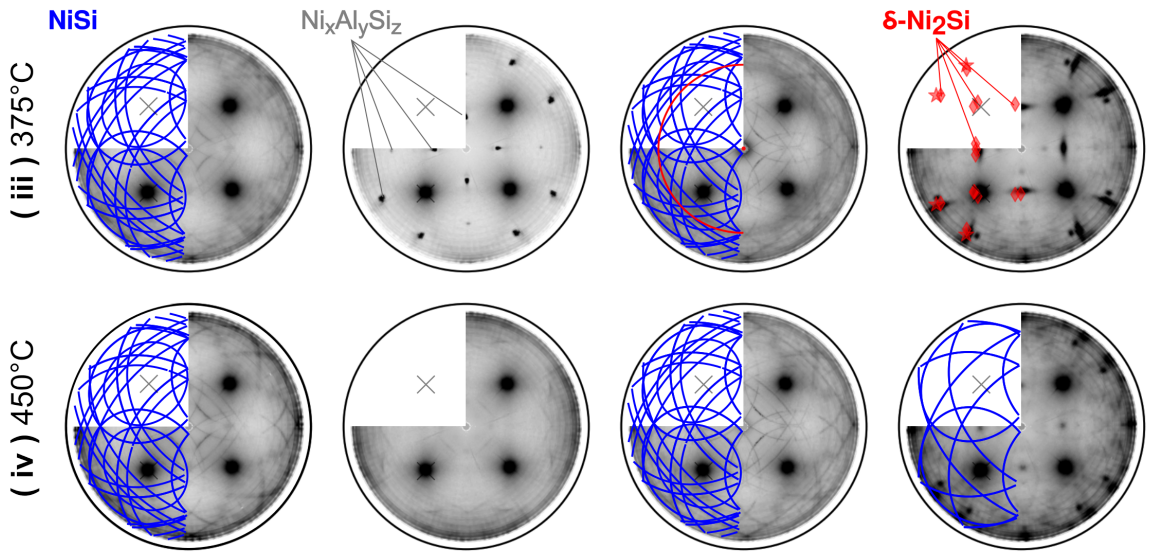

Figure 2: A selection of the aquired pole-figure dataset for alloyed and unalloyed $9 \mathrm{~nm} \mathrm{Ni}$ films, displaying the integrated diffraction intensities around $2 \theta=45.5^{\circ} \pm 0.4^{\circ}$. These images examplify the observed phases and their textures. The identified silicide textures are overlapped on the left half of the dataset (using the symbols defined in tables 23 and 4 . The $\mathrm{Si}(220)$ diffraction peak is always visable and indicated with a gray cross. 
Table 2: Overview of observed epitaxial orientations of the $\theta-\mathrm{Ni}_{2} \mathrm{Si}$ phase for all 3 and $9 \mathrm{~nm}$ films (symbols used in figures 2 and 8 . The angular mismatch between the film and substrate, as calculated from the proposed alignments, are given in terms of $\Delta \chi$ and $\Delta \phi$.

\begin{tabular}{cccc}
\hline Symbol & Plane alignments & $\Delta \chi\left(^{\circ}\right)$ & $\Delta \phi\left(^{\circ}\right)$ \\
\hline $\mathrm{A}_{\theta}(\triangle)$ & $(02 \overline{2} 1)_{\theta} \sim / /(\overline{2} 22)_{S i}$ & 0.2 & 0.0 \\
& $(\overline{2} 110)_{\theta} \sim / /(220)_{S i}$ & 0.1 & 0.1 \\
& $(000 \overline{1})_{\theta} \sim / /(1 \overline{1} 1)_{S i}$ & 0.6 & 0.8 \\
$\mathrm{~B}_{\theta}(\Delta)$ & $(02 \overline{2} 1)_{\theta} \sim / /(222)_{S i}$ & 0.2 & 0 \\
& $(\overline{2} 110)_{\theta} \sim / /(\overline{2} 20)_{S i}$ & 0.1 & 0.1 \\
& $(0001)_{\theta} \sim / /(\overline{1} \overline{1} 5)_{S i}$ & 0.16 & 0.85 \\
\hline
\end{tabular}

Overview of observed textures. The pole figures of unannealed samples (not shown) indicate that the crystalline grains of $\mathrm{Ni}, \mathrm{Ni}(\mathrm{Al})$ and $\mathrm{Ni}(\mathrm{Pt})$ do not have a strong preferential orientation, and as such, the pole figures do not show significant changes in intensity as a function of $\chi$ or $\phi . \mathrm{Ni}(\mathrm{Co})$, on the other hand, exhibits higher diffraction signal at the center of the pole figure (comparable to Fig. 22-i) and a diffraction ring near $\chi=70^{\circ}$. The concentric diffraction ring is typically observed for a fiber texture, for which a specific crystalline direction acts as a rotation axis perpendicular to the sample's surface. The higher diffraction at the center of the pole figure indicates that the Ni-lattice (111) plane is oriented perpendicular to this center of rotation, which coincides with a diffraction ring at $\chi=70.5^{\circ}$ due to the cubic symmetry of the $\mathrm{Ni}$ unit cell (e.g. the angle between $\mathrm{Ni}(111)$ and $\mathrm{Ni}(11 \overline{1})$ ), and also explains the diffraction ring of the $\mathrm{Ni}(200)$ plane (not shown) at $\chi=54^{\circ}$.

Annealing these samples up to $200{ }^{\circ} \mathrm{C}$ provides a slight increase of small diffraction spots (figure $2 \mathrm{a}-\mathrm{i}$ ), indicating the presence of an epitaxial phase. The same diffraction pattern is observed for all samples annealed at $300{ }^{\circ} \mathrm{C}$, and is identical to the epitaxial phase observed for $3 \mathrm{~nm}$ films at $350^{\circ} \mathrm{C}[9$, 26] which was identified as an epitaxial $\theta-\mathrm{Ni}_{2} \mathrm{Si}$. The observed diffraction spots of $\theta-\mathrm{Ni}_{2} \mathrm{Si}$ can be explained by two different epitaxial alignments with the Si substrate (Table 2, where $\mathrm{A}_{\theta}$ has the highest observed diffracted intensity) [27, 26], whose positions are overlaid by green circles in figures $2 \mathrm{i}$. The approximate alignment 

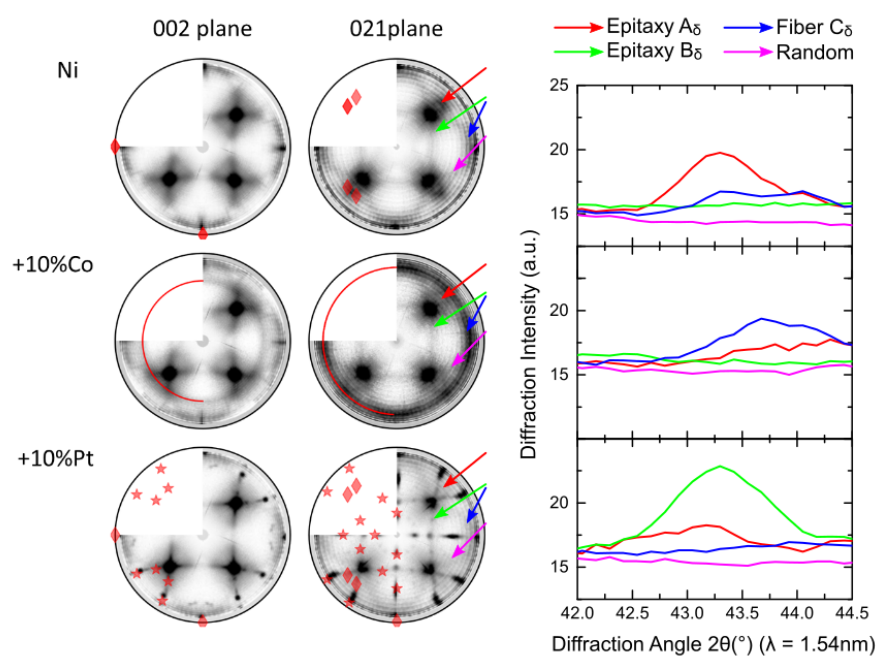

Figure 3: Left: The pole figures which contain diffraction of $\delta-\mathrm{Ni}_{2} \mathrm{Si}$ show that both epitaxial $(\mathrm{Ni}, \mathrm{Ni}(\mathrm{Pt}))$ and fiber-aligned $(\mathrm{Ni}, \mathrm{Ni}(\mathrm{Co})$ silicide are present, depending on the composition of the initial $9 \mathrm{~nm} \mathrm{Ni}$ film. The red, green and blue arrows indicate positions which are uniquely correlated with a specific texture type. The pink arrow is choosen as such that none of the observed textures should diffract here. Right: The diffraction at these positions is plotted as a function of $2 \theta$ for the (021) plane. Note that no $\delta-\mathrm{Ni}_{2} \mathrm{Si}$ diffraction is observed at orientations corresponding with randomly-aligned grains.

for the $\{0001\}$ planes are also given to initiate further discussion. It is interesting to note that we observed no diffraction signal originating from $\theta-\mathrm{Ni}_{2} \mathrm{Si}$ that is aligned in a random distribution with the substrate, which explains their absence in the conducted in situ XRD measurements.

The $\delta-\mathrm{Ni}_{2} \mathrm{Si}$ phase can be observed for $\mathrm{Ni}, \mathrm{Ni}(\mathrm{Co})$ and $\mathrm{Ni}(\mathrm{Pt})$ in figures 2 a-ii, c-ii and d-iii films but did not occur for any quenched $\mathrm{Ni}(\mathrm{Al})$ sample. Remarkably, the texture of the $\delta-\mathrm{Ni}_{2} \mathrm{Si}$ is significantly affected by alloying the $\mathrm{Ni}$ film. Additional pole figures of the $\delta-\mathrm{Ni}_{2} \mathrm{Si}(002)$ and (021) planes are shown in figure 3. Two different texture types are observed: epitaxial alignment for unalloyed $\mathrm{Ni}$ and $\mathrm{Ni}(\mathrm{Pt})$, and fiber-aligned $\delta-\mathrm{Ni}_{2} \mathrm{Si}$ for $\mathrm{Ni}(\mathrm{Co})$. For unalloyed $\mathrm{Ni}$, the preferential orientation can be mostly described as an epitaxial alignment, in addition to a low-intense fiber alignment. No diffraction is observed from randomly-oriented grains, as indicated in the right side of figure 3 The 
Table 3: Overview of observed epitaxial $\left(\mathrm{A}_{\delta}, \mathrm{B}_{\delta}\right)$ and fiber $\left(C_{\delta}\right)$ orientation of the $\delta-\mathrm{Ni}_{2} \mathrm{Si}$ phase as observed for $9 \mathrm{~nm} \mathrm{Ni}, \mathrm{Ni}(\mathrm{Co})$ and $\mathrm{Ni}(\mathrm{Pt})$ films (symbols used in figures 2 and 3 ). The angular mismatch between the film and substrate, as calculated from the proposed alignments, are given in terms of $\Delta \chi$ and $\Delta \phi$.

\begin{tabular}{ccccc}
\hline Symbol & Plane alignments & $\Delta \chi\left(^{\circ}\right)$ & $\Delta \phi\left(^{\circ}\right)$ & occurrence \\
\hline $\mathrm{A}_{\delta}(\diamond)$ & $(001)_{\delta} \sim / /(110)_{S i}$ & 0 & 0 & $\mathrm{Ni}, \mathrm{Ni}(\mathrm{Pt})$ \\
& $(301)_{\delta} \sim / /(20 \overline{2})_{S i}$ & 1.9 & 0.8 & \\
$(0 \overline{1} 0)_{\delta} \sim / /(1 \overline{1} 1)_{S i}$ & 0 & 0.4 & \\
$\left.\mathrm{~B}_{\delta}(\star)\right)$ & $(001)_{\delta} \sim / /(110)_{S i}$ & 0 & 0 & $\mathrm{Ni}(\mathrm{Pt})$ \\
& $(121)_{\delta} \sim / /(20 \overline{2})_{S i}$ & 2.7 & 1.4 & \\
$(010)_{\delta} \sim / /(\overline{1} \overline{1} 5)_{S i}$ & 0.2 & 0.4 & \\
$\mathrm{C}_{\delta}(-)$ & $(301)_{\delta} \sim / /(00 \overline{2})_{S i}$ & 0.0 & 0.0 & $\mathrm{Ni}(\mathrm{Co})$ \\
\hline
\end{tabular}

identification of the epitaxial alignments observed within the $\mathrm{Ni}$ and $\mathrm{Ni}(\mathrm{Pt})$ samples is given in table 3 . The fiber-texture, which was more clearly observed in the $\mathrm{Ni}(\mathrm{Co})$ sample, was determined to be originating from a $(301)_{\delta} / /(002)_{S i}$ alignment. Gaudet et al. also observed this fiber alignment of $\delta-\mathrm{Ni}_{2} \mathrm{Si}$ for annealed, unalloyed, Ni films of $30 \mathrm{~nm}$ thickness [28]. The origin of the observed diffraction peak during the in situ XRD measurements (Fig. 11) is explained by grains that are oriented along the fiber-alignment, as the set-up was detecting planes which were parallel to the substrate's surface (i.e. Si\{001\}).

For $\mathrm{Ni}(\mathrm{Al})$, an epitaxial phase is observed at $375^{\circ} \mathrm{C}$ (labelled as $\mathrm{Ni}_{x} \mathrm{Al}_{y} \mathrm{Si}_{z}$ in Fig. 2p-iii), in agreement with the phase observed in a recent study on the $\mathrm{Ni}(\mathrm{Al})$ silicide formation process for thicker Ni films [29]. Its occurrence is indicated by additional diffraction peaks at $2 \theta=22.4,24.9,32.1,36.7$ and $38.6^{\circ}$, but no match could be found with reference diffraction patterns in the JCPDS database, preventing a clear phase identification. The ternary Ni-Al-Si phase diagram [30, 31, 32] does include several ternary phases, and not all of the crystal structures are available in the literature.

At higher temperatures, the NiSi phase is present within all of the samples. Pole figures for this NiSi phase (Fig 2) exhibit a complex pattern of circular features, which is indicative for the axiotaxial texture previously discussed by 


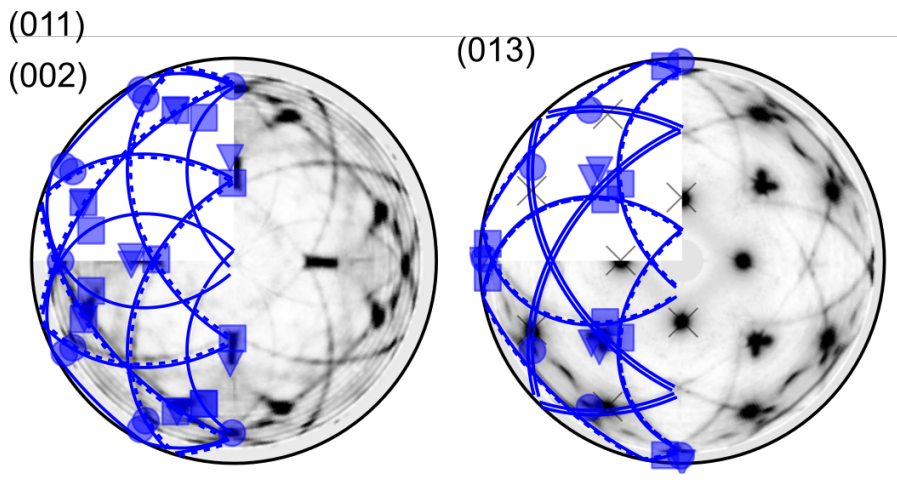

Figure 4: The $9 \mathrm{~nm} \mathrm{Ni}(\mathrm{Pt})$ pole figures which display diffraction of NiSi contain both axiotaxial (circular lines) as well as epitaxial (local spots of higher intensity) features. The overlayed epitaxies are listed in table 4

Table 4: Overview of observed epitaxial orientation of the NiSi phase (symbols used in Fig. 4. The angular mismatch between the film and substrate, as calculated from the proposed alignments, are given in terms of $\Delta \chi$ and $\Delta \phi$.

\begin{tabular}{ccccc}
\hline Symbol & Plane alignments & $\Delta \chi\left(^{\circ}\right)$ & $\Delta \phi\left(^{\circ}\right)$ & occurrence \\
\hline $\mathrm{A}_{N i S i}(\square)$ & $(\overline{1} 0 \overline{1})_{N i S i} \sim / /(101)_{S i}$ & 0 & 0 & $\mathrm{Ni}(\mathrm{Pt}), 9 \& 3 \mathrm{~nm}$ \\
$(300)_{N i S i} \sim / /(2 \overline{2} \overline{2})_{S i}$ & 3.7 & 2.9 & \\
$(010)_{N i S i} \sim / /(10 \overline{1})_{S i}$ & 0 & 0 & \\
$\mathrm{~B}_{N i S i}(\nabla)$ & $(21 \overline{1})_{N i S i} \sim / /(\overline{2} 20)_{S i}$ & 0 & 0.96 & $\mathrm{Ni}(\mathrm{Pt}) 9 \mathrm{~nm}$ \\
& $(013)_{N i S i} \sim / /(1 \overline{1} 0)_{S i}$ & 0 & 0 & \\
$(100)_{N i S i} \sim / /(111)_{S i}$ & 4.78 & 0 & \\
$\mathrm{C}_{N i S i}(\bigcirc)$ & $(211)_{N i S i} \sim / /(02 \overline{2})_{S i}$ & 1.36 & 3.93 & $\mathrm{Ni}(\mathrm{Pt}), 9 \mathrm{~nm}$ \\
& $(013)_{N i S i} \sim / /(\overline{1} 10)_{S i}$ & 3.13 & 0.1 & \\
$(100)_{N i S i}$ & $\sim / /(\overline{1} \overline{1} \overline{\bar{s}})_{S i}$ & 0.0 & 4.1 & \\
\hline
\end{tabular}



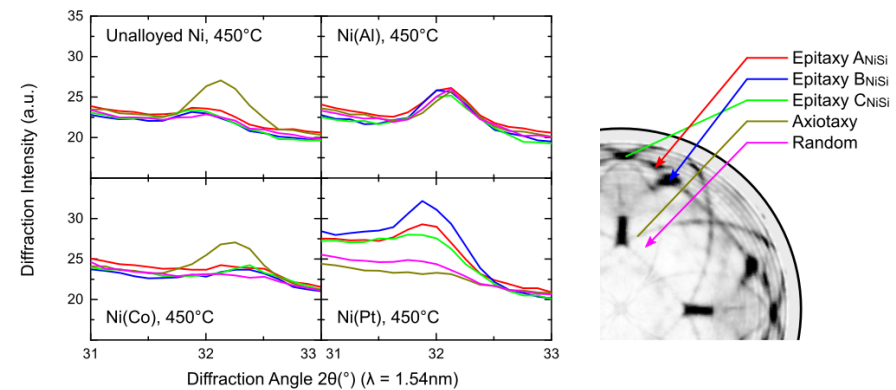

Figure 5: (color version online)The XRD intensity is displayed as a function of $2 \theta$ for different regions in the reciprocal space, which are selected to represent the different textures observed for NiSi.

Detavernier et al. [33]. The axiotaxy originates from the preferential alignment of lattice planes with a similar d-spacing across the interface. Two axiotaxial axes are observed here: $(202)_{N i S i} / /(202)_{S i}$ and $(211)_{N i S i} / /(202)_{S i}$, in agreement with our earlier work 33]. The patterns for the unalloyed Ni sample are almost identical to the patterns observed from a $\mathrm{Ni}(\mathrm{Co})$ sample (Fig. 2a,b-iii,iv). The intensity of these circular features is, however, significantly reduced for the $\mathrm{Ni}(\mathrm{Al})$ sample, where the NiSi phase diffracts more uniformly for every $\chi$ and $\phi$ value, indicating a more random distribution of the grains' orientations (Fig. 2 b-iv). NiSi formed from the $\mathrm{Ni}(\mathrm{Pt})$ sample also contains local diffraction spots of higher intensity along the circular features, indicating that the rotational freedom, which is allowed along the axiotaxial rotation axis, is reduced with a second alignment condition, thus pinning these grains in an epitaxial alignment (Fig. 2d-iv). The fitted epitaxial components are displayed in figure 4 and listed in Table 4 .

Figure 5 allows a more quantitative comparison between the different textures of the $\mathrm{NiSi}$ phase. For unalloyed $\mathrm{Ni}$ (and $\mathrm{Ni}(\mathrm{Co})$ ), it is clear that the diffraction along the axiotaxial line has the highest intensity, whereas the regions associated with epitaxial alignment do not diffract more than a region which is corresponding to a randomly-oriented grain. As such, there is no preference for the grains to align themselves along this epitaxial texture. A similar 

not contain any distinguishable change in diffraction signal, and thus doesn't provide any information on the SPR, similar to the results of De Keyser et 
(a) Unalloyed $\mathrm{Ni}$

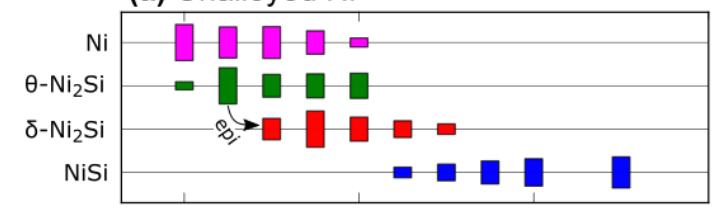

(b) $\mathrm{Ni}(10 \% \mathrm{Al})$

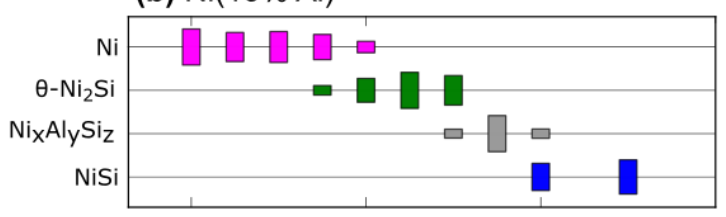

(c) $\mathrm{Ni}(10 \% \mathrm{Co})$

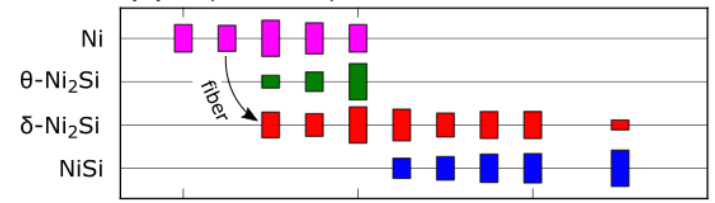

(d) $\mathrm{Ni}(10 \% \mathrm{Pt})$

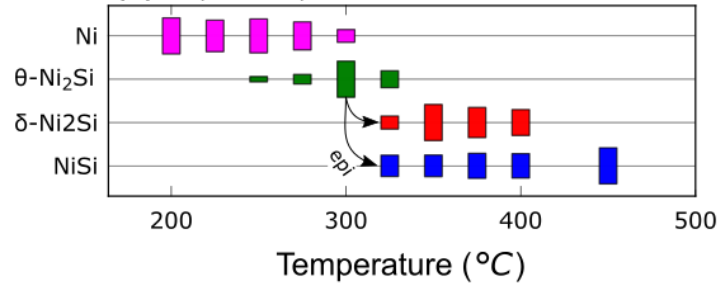

Figure 6: Overview of the observed silicides' diffraction intensity as a function of temperature for pure and alloyed $9 \mathrm{~nm} \mathrm{Ni}$ films. The observed intensities are proportional to the height and normalised to the maximum occuring intensity per sample. Arrows indicate examples of texture inheritance across multiple phases, as explained in the discussion. 


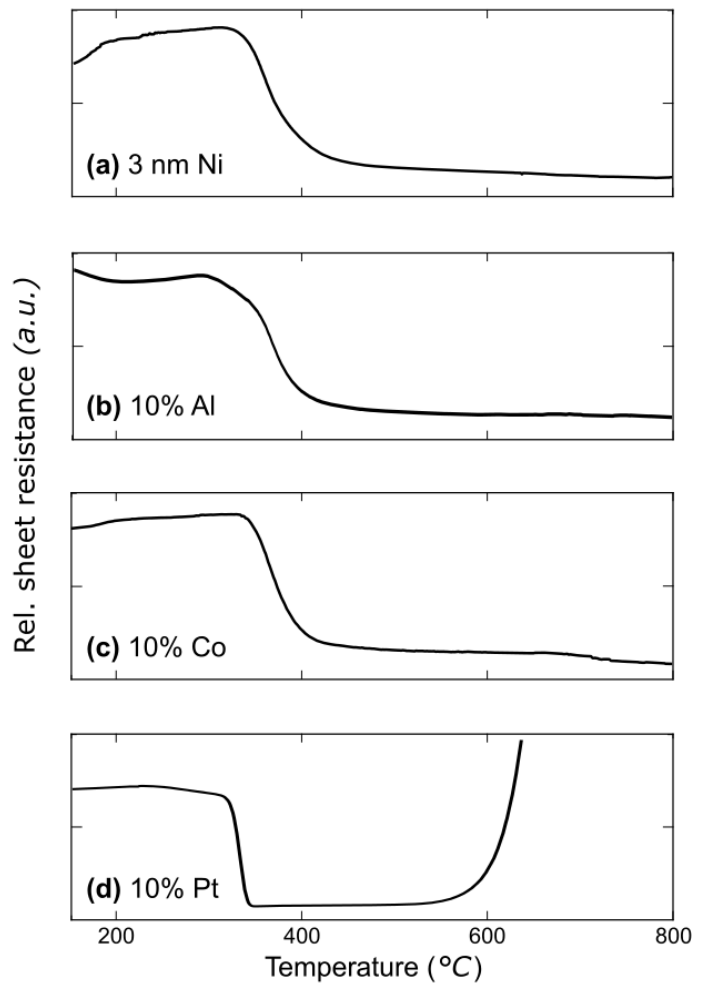

(e) Pole figure quenches

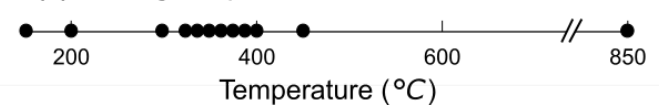

Figure 7: Relative evolution of the sheet resistance of $3 \mathrm{~nm}$ Ni films with variable as-deposited composition, as measured through in situ sheet resistance measurements on SOI substrates. The bottom panel (e) shows the quenching temperatures of the samples prepared for ex situ pole-figure measurements, in addition to a room-temperature sample. 
al. 9]. Alternatively, in situ sheet resistance measurements can be used to

the formation of $\mathrm{NiSi}$ is only observed for the $\mathrm{Ni}(\mathrm{Pt})$ sample, coinciding with the consumption of $\theta-\mathrm{Ni}_{2} \mathrm{Si}$ around $325^{\circ} \mathrm{C}$. Similar to the $9 \mathrm{~nm} \mathrm{Ni}(\mathrm{Pt})$ film, NiSi forms with clear epitaxial features along epitaxial rings (Table 4 ). For the $3 \mathrm{~nm}$ $\mathrm{Ni}, \mathrm{Ni}(\mathrm{Al})$ and $\mathrm{Ni}(\mathrm{Co})$ as-deposited samples, epitaxial $\theta-\mathrm{Ni}_{2} \mathrm{Si}$ is also present, 325 but no silicide phase appears while $\theta-\mathrm{Ni}_{2} \mathrm{Si}$ is consumed. No other phases, such as as-deposited $\mathrm{Ni}, \delta-\mathrm{Ni}_{2} \mathrm{Si}$ or $\mathrm{NiSi}_{2}$, could be observed in any of the quenched $3 \mathrm{~nm}$ samples.

We can assume that the slow consumption of $\theta-\mathrm{Ni}_{2} \mathrm{Si}$ for $\mathrm{Ni}, \mathrm{Ni}(\mathrm{Al})$ and $\mathrm{Ni}(\mathrm{Co})$ is associated with the formation of epitaxial $\mathrm{NiSi}_{2}$, based on the liter- 


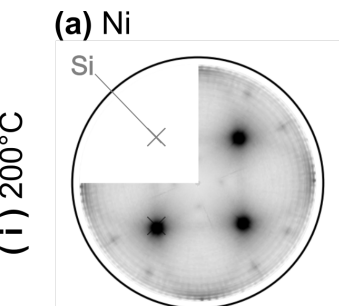

(b) $\mathrm{Ni}+10 \% \mathrm{Al}$
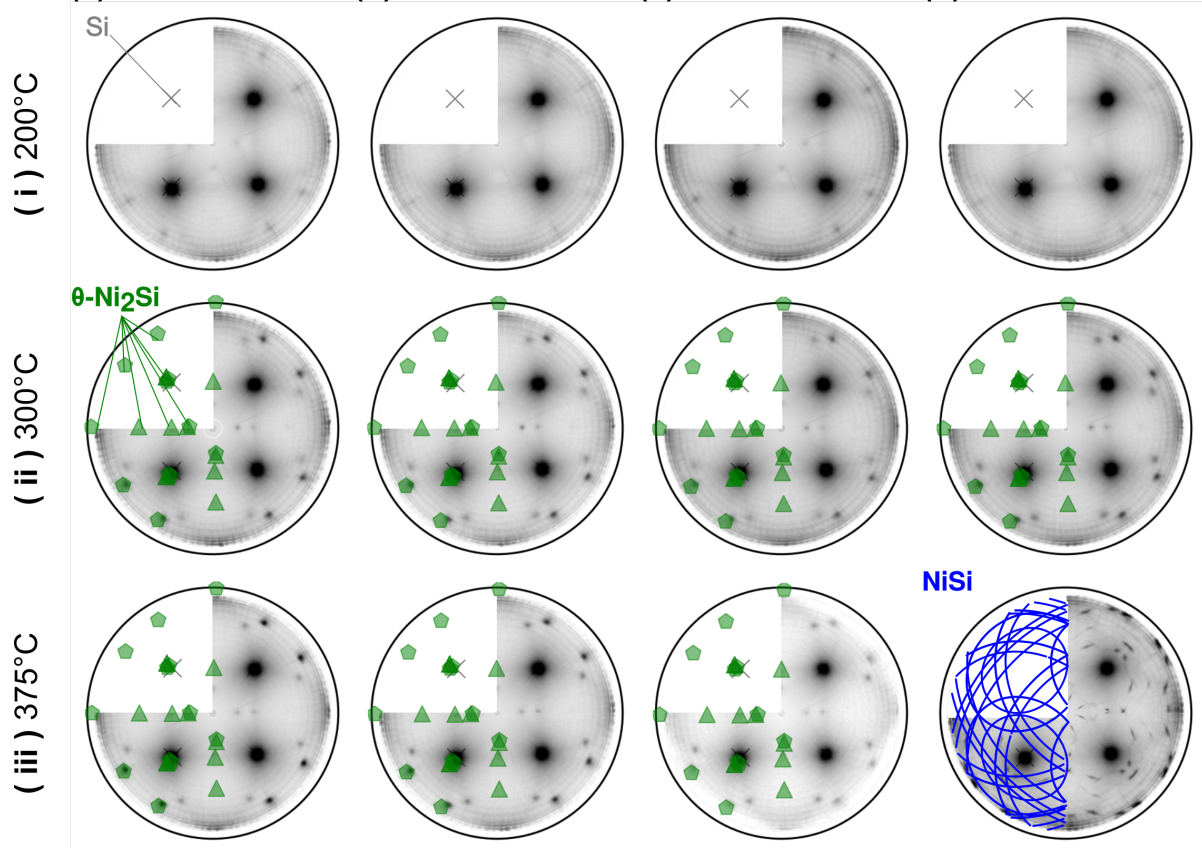

NiSi
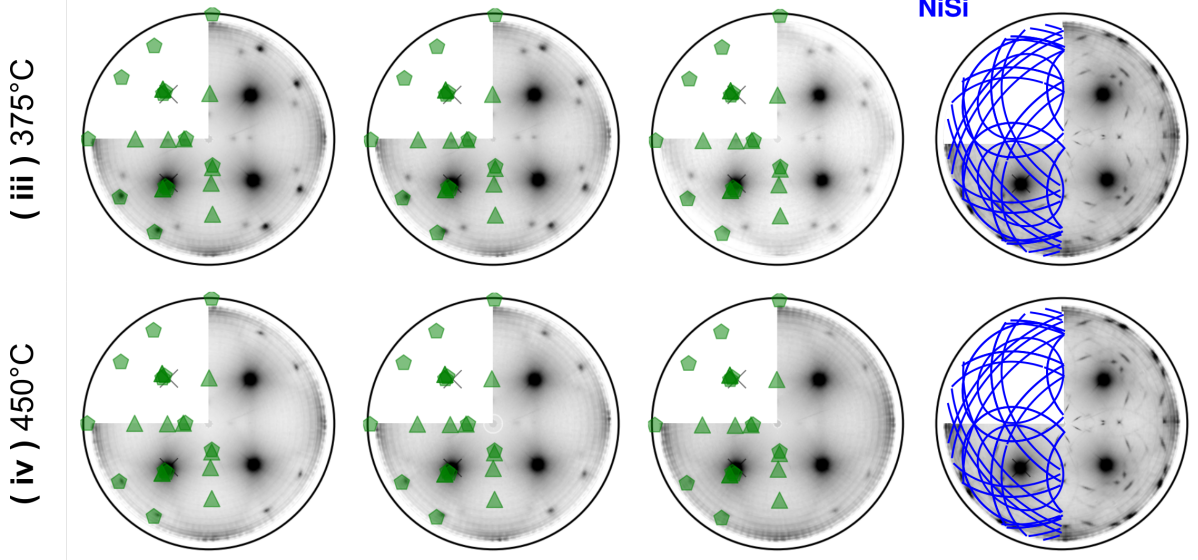

Figure 8: A selection of the aquired pole-figure dataset for alloyed and unalloyed $3 \mathrm{~nm}$ Ni films, displaying the integrated diffraction intensities $2 \theta=45.5^{\circ} \pm 0.4^{\circ}$. These images examplify the observed phases and their textures. The identified silicide textures are overlapped on the left half of the dataset (using the symbols defined in tables 2 and 4 ). The $\mathrm{Si}(220)$ diffraction peak is always visable and indicated with a gray cross. 
(a) Unalloyed $\mathrm{Ni}$

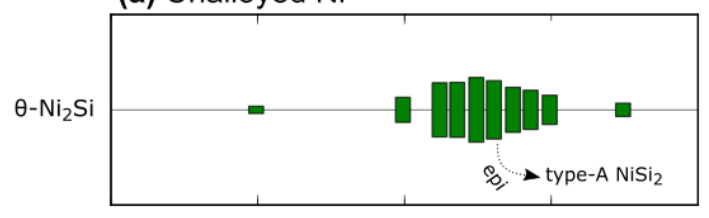

(b) $\mathrm{Ni}(10 \% \mathrm{Al})$

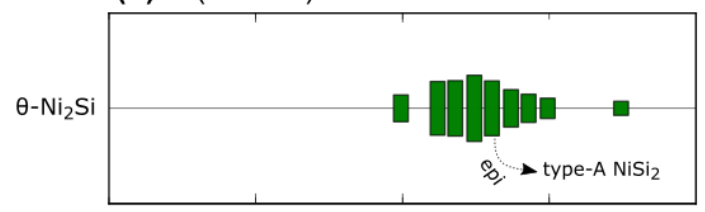

(c) $\mathrm{Ni}(10 \% \mathrm{Co})$

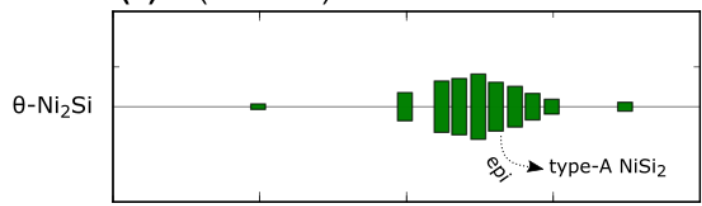

(d) $\mathrm{Ni}(10 \% \mathrm{Pt})$

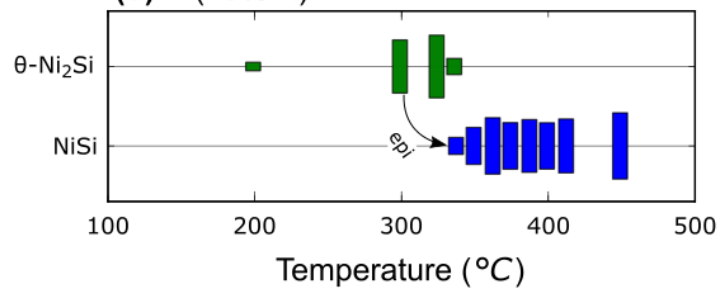

Figure 9: Overview of the observed silicides' diffraction intensity as a function of temperature for pure and alloyed $3 \mathrm{~nm} \mathrm{Ni}$ films. The observed intensities are proportional to the height and normalised to the maximum occuring intensity per sample. Arrows indicate examples of texture inheritance across multiple phases, as explained in the discussion. 
330

the in situ sheet resistance measurements: as $\mathrm{NiSi}_{2}$ exhibits a lower resistance due to an increase in layer thickness and an assumed lower bulk-resistivity than $\theta-\mathrm{Ni}_{2} \mathrm{Si}$. Due to the very similar crystal structure of $\mathrm{NiSi}_{2}$ and the $\mathrm{Si}$ substrate (with only $0.46 \%$ difference in lattice parameter), the diffraction angles in an identical alignment with the Si substrate for such thin initial Ni films, i.e. $(100)_{N i S i 2} / /(100)_{S i}$ and $(001)_{N i S i 2} / /(001)_{S i}$ (also known as the type-A epitaxial alignment of $\mathrm{NiSi}_{2}$ ). This particular orientation is not observable from our ex situ pole-figure measurements, as the recorded scattered intensity is highly dominated by the vicinity of the Si substrate Bragg peaks. However, TEMbased studies in the literature observed the type-A epitaxial alignment of $\mathrm{NiSi}_{2}$ [12, 26, 10].

The formation and consumption of the observed phases is illustrated in figure 9. It is clear that the epitaxial $\theta-\mathrm{Ni}_{2} \mathrm{Si}$ slowly is consumed at the same decreases.

\section{Discussion}

Our in situ XRD and ex situ pole-figure measurements clearly indicate that alloying not only influences the temperature windows in which specific silicide phases occur, but also can change the phase sequence (e.g. through the formation of NiSi in the ultrathin thickness regime with Pt alloying) as well as the preferential orientation of the occurring phases. We first discuss the observed change in phase sequence and temperature window in the context of alloy solubility. Thereafter, we discuss and rationalise the observed preferential orientations.

\section{Influence of alloying on phase formation}

The temperature windows of the presence of $\delta-\mathrm{Ni}_{2} \mathrm{Si}, \theta-\mathrm{Ni}_{2} \mathrm{Si}$, and $\mathrm{NiSi}$ are significantly influenced through alloying for $9 \mathrm{~nm}$ Ni films, as depicted in figures 
Table 5: The maximum atomic concentrations of $\mathrm{Al}$, Co and Pt ternary elements in nickel silicides. * indicates that a full replacement of $\mathrm{Ni}$ is possible. Arrows indicate an observed increased $(\nearrow)$ or decreased $(\searrow)$ width of the temperature window of the phase presence, according to ex situ pole-figure and in situ XRD measurements (Fig. 1] 6)

\begin{tabular}{|c|c|c|c|c|c|c|}
\hline \multirow{2}{*}{$\begin{array}{c}\text { Alloy: } \\
\delta-\mathrm{Ni}_{2} \mathrm{Si}\end{array}$} & \multicolumn{2}{|c|}{$\mathrm{Al}(\%)$} & \multicolumn{2}{|c|}{ Co $(\%)$} & \multicolumn{2}{|c|}{$\mathrm{Pt}(\%)$} \\
\hline & 20 & - & $66^{*}$ & $\nearrow$ & $<5$ & $\searrow$ \\
\hline$\theta-\mathrm{Ni}_{2} \mathrm{Si}$ & 20 & $\nearrow$ & unknown & $\searrow$ & soluble & - \\
\hline $\mathrm{NiSi}$ & 1.5 & $\searrow$ & 10 & $\searrow$ & $50^{*}$ & $\nearrow$ \\
\hline $\mathrm{NiSi}_{2}$ & 29 & - & $33^{*}$ & $\nearrow$ & $<5$ & - \\
\hline Ref. & 30 & 32 & 39 & & 40,36, & 41 \\
\hline
\end{tabular}

1 and 6. For example, we observe that the formation of $\delta-\mathrm{Ni}_{2} \mathrm{Si}$ is delayed when $\mathrm{Pt}$ is present as alloying element, whereas Co, on the other hand, seems to stabilise the $\delta-\mathrm{Ni}_{2} \mathrm{Si}$ phase up to higher temperatures. We correlate these changes in the observed temperature windows with the solubility of the alloying element in the silicide phase (the maximum atomic concentration that can be in solid-solution within the silicide compounds are tabulated in Table 5p together with the observed changes of the phases' existence temperature windows. This effect can be understood within the framework of classical nucleation theory [42, where the energetic barrier for a phase to nucleate is related to the change in enthalpy of formation, the change in entropy and the change in interfacial energy upon phase transition. The enthalpy of formation of these nickel silicides are comparable: $\delta-\mathrm{Ni}_{2} \mathrm{Si}:-46.9, \mathrm{NiSi}:-42.4, \mathrm{NiSi}_{2}: 29.3 \mathrm{~kJ} / \mathrm{mol}$ of atoms [43. However, the nucleation barrier to form these phases will be influenced through alloying. An alloy with low solubility in a particular silicide phase will indeed hinder the formation of this new phase, as the alloying element should first be expelled before the new crystal structure can nucleate. This effect has in fact been observed by Mangelinck et al. through atom probe tomography, as $\mathrm{Pt}$ is segregated to the grain boundaries of $\delta-\mathrm{Ni}_{2} \mathrm{Si}$, also known as the snowplough effect [18, 19]. On the other hand, a soluble alloy will enable an increase in entropy within a silicide grain, and as such, potentially lower the nucleation energy barrier to form this new phase. Through this argument, 


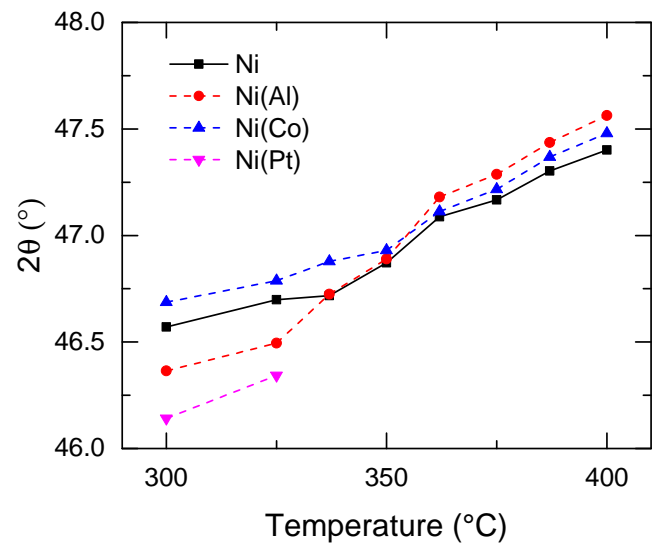

Figure 10: (color online) Evolution of the $2 \theta$ position of an epitaxial peak of the $\theta-\mathrm{Ni}_{2} \mathrm{Si}$ (near $\chi=18^{\circ}$ and $\phi=0^{\circ}$ ) as observed in $3 \mathrm{~nm} \mathrm{Ni}$ films.

we can understand several aspects of the observed phase sequence for the $9 \mathrm{~nm}$ films, including the larger temperature window of $\delta-\mathrm{Ni}_{2} \mathrm{Si}$ with Co-alloying, how the same alloy promotes the low-temperature $\mathrm{NiSi}_{2}$ formation, and the delay in NiSi formation through $\mathrm{Al}$ alloying. The solubility argument is, of course, not the only condition for changes in the temperature window (e.g. the absence of $\delta-\mathrm{Ni}_{2} \mathrm{Si}$ when $\mathrm{Al}$ alloying is used). Other thermodynamic parameters, such as interfacial energy through substrate alignment and change in diffusion rates at grain boundaries will also contribute to the observed shifts in temperature windows. This will be discussed further below.

For $3 \mathrm{~nm} \mathrm{Ni}$ layers, it is remarkable that the formation of the epitaxial $\theta$ $\mathrm{Ni}_{2} \mathrm{Si}$ does not seem to be influenced by $\mathrm{Al}$ or Co alloys. Indeed, $\theta-\mathrm{Ni}_{2} \mathrm{Si}$ has similar growth profiles and diffraction intensities for $\mathrm{Ni}, \mathrm{Ni}(\mathrm{Al})$ and $\mathrm{Ni}(\mathrm{Co})$ samples at this thickness, and its formation does not seem to be hindered by the alloying element. One may argue that the lattice of $\theta-\mathrm{Ni}_{2} \mathrm{Si}$, which can cover from 33 to $42 \% \mathrm{Si}$ according to the binary $\mathrm{Ni}-\mathrm{Si}$ phase diagram [36], can easily adapt to the incorporation ternary atoms. This would imply a significant strain in the lattice, and by consequence a shift in the diffraction angle of $\theta$ $\mathrm{Ni}_{2} \mathrm{Si}$. To verify this, we fitted the $2 \theta$ peak positions of the $\theta-\mathrm{Ni}_{2} \mathrm{Si}$ epitaxial 
peak at $\chi=18^{\circ}$, which has a high diffraction intensity and its low elevation angle $\chi$ ensures a decent resolution in $2 \theta$ (Fig. 10). Two significant changes can be observed. (i) As function of temperature, the diffraction angle increases linearly, corresponding to a decrease in lattice parameters from 1.95 to $1.92 \AA$ over a $100{ }^{\circ} \mathrm{C}$ temperature range. This decrease can be related to a change in film strain, composition or due to a negative coefficient of thermal expansion of at least one lattice parameter. The reduction of the crystalline lattice is significantly higher when compared to other silicides with a negative coefficient of thermal expansion [44. Unfortunately, too little diffraction planes with sufficient intensity were observed in these measurements to further investigate this effect. (ii) As function of alloying species, one can observe that the diffraction peak is systematically higher in $2 \theta$ when Co alloying is used in comparison with an unalloyed sample, which is similar to the effect of Co-alloying on the NiSi or $\mathrm{NiSi}_{2}$ phase [45]. $\mathrm{Al}$ and $\mathrm{Pt}$ seem to increase the initial $\theta-\mathrm{Ni}_{2} \mathrm{Si}$ lattice spacing (corresponding to a lower $2 \theta$ angle), and the subsequent evolution of the $\mathrm{Ni}(\mathrm{Al})$ sample indicates a complex change in the films' composition or strain. This illustrates the flexibility of the $\theta-\mathrm{Ni}_{2} \mathrm{Si}$ to accommodate alloying elements and compositional gradients, which possibly explains why no significant change can be observed in the growth profile within the ultrathin film region. This is again corroborated through the texture of $\theta-\mathrm{Ni}_{2} \mathrm{Si}$ : although the texture of other silicides changes remarkably with the addition of a ternary element (Figures 344, the same epitaxy is always observed for $\theta-\mathrm{Ni}_{2} \mathrm{Si}$, independent of as-deposited composition or thickness (Figures 208).

Influence of alloying on preferential orientation - examples of texture inheritance

Not only the temperature windows of the observed phases is influenced through alloying, but also the silicides' preferential orientation with respect to the $\mathrm{Si}$ substrate. The most remarkable changes can be found in the texture of $\delta-\mathrm{Ni}_{2} \mathrm{Si}$, where an epitaxial orientation is observed for $\mathrm{Ni}$ and $\mathrm{Ni}(\mathrm{Pt})$ and a fiber texture for $\mathrm{Ni}(\mathrm{Co})$ (Fig. 3 and Table 3). Moreover, the overview of polefigure measurements (Fig. 2) illustrates that the fiber texture is most clearly 
(a) $\theta-\mathrm{Ni}_{2} \mathrm{Si}$ to $\delta-\mathrm{Ni}_{2} \mathrm{Si}$ transition
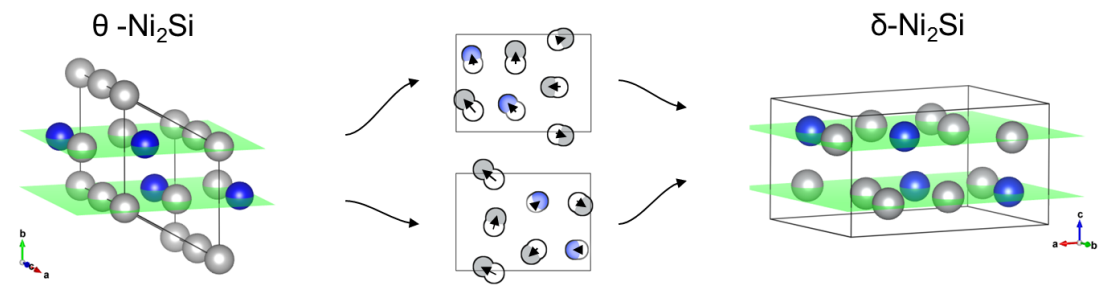

(b) $\theta-\mathrm{Ni}_{2} \mathrm{Si}$ to $\mathrm{NiSi}$ transition
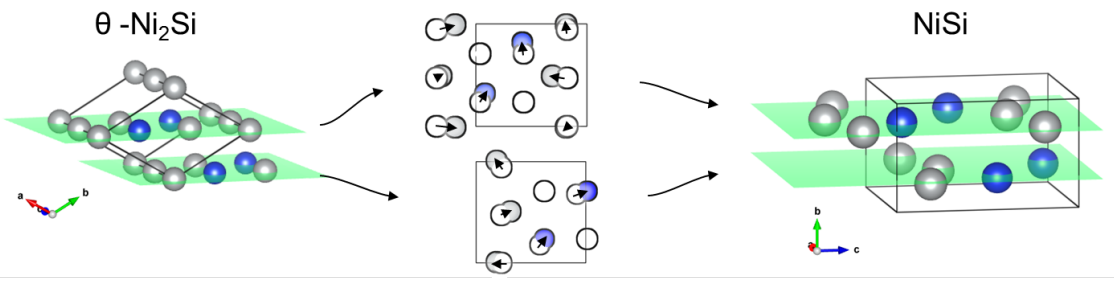

Figure 11: The transition from (a) $\theta-\mathrm{Ni}_{2} \mathrm{Si}$ to $\delta-\mathrm{Ni}_{2} \mathrm{Si}$ or from (b) $\theta-\mathrm{Ni}_{2} \mathrm{Si}$ to NiSi involves only minimal atomic movement, thus possibly introducing texture inheritence.

present in the as-deposited cobalt-alloyed nickel layer, as well as in subsequent $\delta-\mathrm{Ni}_{2} \mathrm{Si}$. This could indicate that the texture of a specific silicide is influenced by the orientation of the preceding phase. Indeed, Gaudet et al. 6] reported, for the unalloyed nickel silicide solid-phase reaction, that a transformation from one phase to another phase could coincide in an inheritance of fiber-textures, provided that the crystal structures are similar. A similar reasoning applied here for a fiber-inheritance between the as-deposited, cobalt-alloyed $\mathrm{Ni}(111)$ fiber-axis and $\delta-\mathrm{Ni}_{2} \mathrm{Si}(301)$, where the respective fiber planes evolve from a d-spacing of 2.03 to $1.99 \AA$, allowing plane-to-plane matching at the nucleation interface between cobalt-alloyed nickel grains and $\delta-\mathrm{Ni}_{2} \mathrm{Si}$.

A more remarkable texture inheritance is indicated by our measurements on some of the observed epitaxial orientations. We explain this phenomenon on the basis of the epitaxially textured $\delta-\mathrm{Ni}_{2} \mathrm{Si}$ when $\mathrm{Pt}$ is added as a ternary element. The epitaxial alignment of $\delta-\mathrm{Ni}_{2} \mathrm{Si}$, which is not present when $\delta-\mathrm{Ni}_{2} \mathrm{Si}$ is formed 
from an unalloyed Ni film (Fig. 3), would be hard to explain on solubility arguments alone, as the solubility of $\mathrm{Pt}$ in $\delta-\mathrm{Ni}_{2} \mathrm{Si}$ is very low. However, this phase is formed at expense of the preceding, epitaxially-aligned, $\theta-\mathrm{Ni}_{2} \mathrm{Si}$ (Fig. ${ }_{445}^{6}$ 6), and thus texture inheritance is possible provided that the crystal structures are related. Indeed, a minimal atomic movement is required to transform the $\theta$ $\mathrm{Ni}_{2} \mathrm{Si}$ into $\delta-\mathrm{Ni}_{2} \mathrm{Si}$, as illustrated in figure 11. The corresponding transforming planes are then: $\{010\}_{\delta} / /\{0001\}_{\theta}$ for the basal plane, and $\{001\}_{\delta} / /\{11 \overline{2} 0\}_{\theta}$ or $\{301\}_{\delta} / /\{11 \overline{2} 0\}_{\theta}$, depending on a rotation of $60^{\circ}$ due to the hexagonal symmetry of $\theta-\mathrm{Ni}_{2} \mathrm{Si}$. These transformation rules well explain the change of $\mathrm{A}_{\theta}$ and $\mathrm{B}_{\theta}$ epitaxy into $\mathrm{A}_{\delta}$ and $\mathrm{B}_{\delta}$, respectively. This is easily seen by transforming the epitaxies from Table 3 into those listed in Table 2 taking into account the symmetry of $\theta-\mathrm{Ni}_{2} \mathrm{Si}$ and the $\mathrm{Si}(001)$ substrate, and that an epitaxial orientation is defined by fixating the orientation of two sets of non-parallel planes. This texture inheritance not only minimises the required atomic mobility for the $\mathrm{Si}$ atoms, but also reduces the interface energy between the nucleated $\delta-\mathrm{Ni}_{2} \mathrm{Si}$ grain and the existing $\theta-\mathrm{Ni}_{2} \mathrm{Si}$ grain through plane-to-plane matching.

The epitaxial alignment of $\mathrm{NiSi}$, which is also observed when $\mathrm{Pt}$ is added to the as-deposited Ni layer, can also be understood through similar epitaxialtexture inheritance arguments. Figure $11 \mathrm{p}$ shows that the transformation from $\theta-\mathrm{Ni}_{2} \mathrm{Si}$ to NiSi is enabled by a minimal movement of the majority of atoms involved, especially for the least-mobile element Si. The transition from compositional $\mathrm{Ni}_{2} \mathrm{Si}$ to $\mathrm{NiSi}$, however, requires the out-diffusion of half of the nickel atoms. Ellner et al. 37] reported that the nickel content within $\theta-\mathrm{Ni}_{2} \mathrm{Si}$ can be as low as 58 at \% Ni, so this transformation is not as abrupt as displayed in figure 11b. The corresponding planes are: $\{100\}_{N i S i} / /\{0001\}_{\theta}$ for the basal plane, and $\{013\}_{N i S i} / /\{11 \overline{2} 0\}_{\theta}$ or $\{010\}_{N i S i} / /\{11 \overline{2} 0\}_{\theta}$. In addition to atomic movement, this transformation requires significant deformation of the unit cells, e.g. the lattice spacing of the $\theta-\mathrm{Ni}_{2} \mathrm{Si}$ basal plane needs to expand from 4.89 to $5.18 \AA$. These plane transformations explain the observed transitions of $\mathrm{A}_{\theta}$ to both $\mathrm{A}_{N i S i}$ and $\mathrm{B}_{N i S i}$ and $\mathrm{B}_{\theta}$ into $\mathrm{C}_{N i S i}$. The fact that the $\mathrm{A}_{\theta} \theta-\mathrm{Ni}_{2} \mathrm{Si}$ orientation results into two slightly different epitaxial phases can be related to the fact 
that the texture inheritance requires some relaxation of the unit cell. It appears that the NiSi (101) and (211) planes along $\mathrm{Si}\{101\}$ orientation match with good alignment. The second orientation cannot match perfectly, due to the relaxation of the unit cell, and as such, the texture inheritance will allow small deviations around the original orientation of $\theta-\mathrm{Ni}_{2} \mathrm{Si}$ through the axiotaxial alignment.

The identified pathways for texture inheritance are depicted in Fig. 6 through arrows from the original phase to the succeeding phase. The absence of texture inheritance, for example when forming $\mathrm{NiSi}$ for the $\mathrm{Ni}(\mathrm{Al})$ sample, can be understood as the $\theta-\mathrm{Ni}_{2} \mathrm{Si}-\mathrm{NiSi}$ phase sequence is interrupted by the formation of the $\mathrm{Ni}_{x} \mathrm{Al}_{y} \mathrm{Si}_{z}$ phase. Similarly, the in situ XRD of $\mathrm{Ni}$ and $\mathrm{Ni}(\mathrm{Co})$ samples show the occurrence of non-epitaxial $\theta-\mathrm{Ni}_{2} \mathrm{Si}$ in a short temperature window just prior to the formation of NiSi. As in situ XRD, in the geometry used in this paper, only detects planes nearly-parallel to the surface, this observation means that the $\theta-\mathrm{Ni}_{2} \mathrm{Si}$ has lost (partially) its epitaxial alignment with the Si substrate, thus loosing the epitaxial template for epitaxial texture inheritance. Gaudet et al. 6] describes how $\theta-\mathrm{Ni}_{2} \mathrm{Si}$ at this temperature inherits its fiber alignment from fiber-aligned $\delta-\mathrm{Ni}_{2} \mathrm{Si}$. The observation of texture inheritance of epitaxial texture (in this paper) and fiber texture (by Gaudet et al. [6]) in both directions between $\theta-\mathrm{Ni}_{2} \mathrm{Si}$ and $\delta-\mathrm{Ni}_{2} \mathrm{Si}$ illustrates the competitive growth of these layers.

Finally, the formation of $\mathrm{NiSi}_{2}$ out of $\theta-\mathrm{Ni}_{2} \mathrm{Si}$ for the ultra-thin, $3 \mathrm{~nm} \mathrm{Ni}$ films also correlates with texture inheritance (Fig. 9). The transformation rules for 495 the formation of type-A epitaxial $\mathrm{NiSi}_{2}$ out of the epitaxial $\mathrm{A}_{\theta} \theta-\mathrm{Ni}_{2} \mathrm{Si}$ can indeed be associated with minimal atomic movement. This is, however, less evident for the transition between $\mathrm{B}_{\theta}$ and $\mathrm{A}_{N i S i_{2}}$. It was previously suggested [10 that the low-temperature $\mathrm{NiSi}_{2}$ formation in the ultra-thin regime, instead of $\mathrm{NiSi}$, is the result of a much lower interface energy. Our observations corroborate this, as one epitaxial phase transforms into another, and by consequence the interface energy remains low throughout the transition both at the heterophase silicon-silicide interface, but also at the interface with the consumed silicide.

This work investigates the altered solid-phase reaction through alloying and 
thickness reduction. The improved thermal and morphological stability of the

silicide contact was already long known in literature [12, 16], and the effect

of texture inheritance reported here further enhances our understanding of the underlying kinetics. A change of in preferential orientation and altered agglomeration behaviour of silicide contacts also have been reported through e.g. reducing the in-plane dimension of the contact [46, 47, removing the crystalline template from the substrate through pre-amorphisation implant [48, 49, 50] or by alternating the available thermal budget during deposition [51, 52] and annealing [53, 54]. The current study therefore indicates that modern experimental techniques can further understand binary and ternary solid-phase reactions.

\section{Conclusions}

The phase formation between thin Ni films of 3 and $9 \mathrm{~nm}$ thickness deposited on $\mathrm{Si}(001)$ was investigated by means of in situ XRD, in situ sheet resistance and ex situ pole-figure measurements. The same measurements were also performed on samples alloyed with 10 at.\% Al, Co and Pt. The measurements allowed to investigate the effect of film thickness and the presence of a ternary element on the phase formation and texture of the thin nickel-silicide layers. Changes in the phase formation sequence could be interpreted on the basis of nucleation theory and the effect of entropy of mixing. Most occurring phases, i.e. the as-deposited $\mathrm{Ni}$ layer, $\delta-\mathrm{Ni}_{2} \mathrm{Si}$ and $\mathrm{NiSi}$, revealed significant different textures upon alloying. Remarkably, $\theta-\mathrm{Ni}_{2} \mathrm{Si}$ was observed with the same epitaxial orientation regardless of as-deposited thickness or alloying element, indicating the high tolerance of the $\theta-\mathrm{Ni}_{2} \mathrm{Si}$ unit cell towards impurities. The preferential orientation of subsequently-occurring silicides indicate the mechanism of texture inheritance during the phase sequence. The latter effect succeeds in explaining the occurrence of specific epitaxial and fiber textures through a transformation of the preceding phases. 


\section{Acknowledgement}

The authors acknowledge the FWO Vlaanderen, the Hercules foundation and BOF-UGent (GOA 01G01513) for providing financial support for this work. This research used resources of the National Synchrotron Light Source, a U.S. Department of Energy (DOE) Office of Science User Facility operated for the DOE Office of Science by Brookhaven National Laboratory under Contract No. 405 DE-AC02-98CH10886. This research used resources of the DiffAbs beamline under guidance of C. Mocuta at the SOLEIL synchrotron, France.

\section{References}

[1] S. Zhang, M. Östling, Metal silicides in CMOS technology: past, present, and future trends, Critical Reviews in Solid State and Materials Sciences 28 (1) (2003) 1-129.

[2] C. Lavoie, F. d'Heurle, C. Detavernier, C. Cabral, Towards implementation of a nickel silicide process for CMOS technologies, Microelectronic Engineering 70 (2) (2003) 144-157.

[3] L. Chen, Silicide technology for integrated circuits, Vol. 5, The Institution of Electrical Engineers, 2004.

[4] C. Lavoie, C. Detavernier, C. Cabral, F. dHeurle, A. Kellock, J. JordanSweet, J. Harper, Effects of additive elements on the phase formation and morphological stability of nickel monosilicide films, Microelectronic Engineering 83 (11) (2006) 2042-2054.

[5] D. Mangelinck, K. Hoummada, I. Blum, Kinetics of a transient silicide during the reaction of Ni thin film with (100) Si, Applied Physics Letters 95 (18) (2009) 1902.

[6] S. Gaudet, C. Coia, P. Desjardins, C. Lavoie, Metastable phase formation during the reaction of Ni films with $\mathrm{Si}$ (001): The role of texture inheritance, Journal of Applied Physics 107 (9) (2010) 093515. 
[7] D. Mangelinck, K. Hoummada, F. Panciera, M. El Kousseifi, I. Blum, M. Descoins, M. Bertoglio, A. Portavoce, C. Perrin, M. Putero, Progress in the understanding of Ni silicide formation for advanced MOS structures, Physica Status Solidi (a) 211 (1) (2014) 152-165.

[8] M. El Kousseifi, K. Hoummada, M. Bertoglio, D. Mangelinck, Selection of the first $\mathrm{Ni}$ silicide phase by controlling the Pt incorporation in the intermixed layer, Acta Materialia 106 (2016) 193-198.

[9] K. De Keyser, C. Van Bockstael, R. Van Meirhaeghe, C. Detavernier, E. Verleysen, H. Bender, W. Vandervorst, J. Jordan-Sweet, C. Lavoie, Phase formation and thermal stability of ultrathin nickel-silicides on $\mathrm{Si}$ (100), Applied Physics Letters 96 (17) (2010) 173503.

[10] Z. Zhang, S. Zhang, B. Yang, Y. Zhu, S. M. Rossnagel, S. Gaudet, A. J. Kellock, J. Jordan-Sweet, C. Lavoie, Morphological stability and specific resistivity of sub-10 $\mathrm{nm}$ silicide films of $\mathrm{Ni} \mathrm{Pt}_{x}$ on Si substrate, Applied Physics Letters 96 (2010) 071915.

[11] J. Luo, Z. Qiu, C. Zha, Z. Zhang, D. Wu, J. Lu, J. Åkerman, M. Östling, L. Hultman, S. Zhang, Surface-energy triggered phase formation and epitaxy in nanometer-thick $\mathrm{Ni}_{1-x} \mathrm{Pt}_{x}$ silicide films, Applied Physics Letters $96(3)$.

[12] R. Tung, J. Poate, J. Bean, J. Gibson, D. Jacobson, Epitaxial silicides, Thin Solid Films 93 (1) (1982) 77-90.

[13] R. Tung, J. Gibson, J. Poate, Formation of Ultrathin Single-Crystal Silicide Films on Si: Surface and Interfacial Stabilization of $\mathrm{Si}_{-} \mathrm{NiSi}_{2}$ Epitaxial Structures, Physical Review Letters 50 (6) (1983) 429.

[14] A. Mouroux, S.-L. Zhang, W. Kaplan, S. Nygren, M. Östling, C. Petersson, Enhanced formation of the $\mathrm{C} 54$ phase of $\mathrm{TiSi}_{2}$ by an interposed layer of molybdenum, Applied Physics Letters 69 (7) (1996) 975-977. 
[15] D. Mangelinck, P. Gas, J. Gay, B. Pichaud, O. Thomas, Effect of Co, Pt, and $\mathrm{Au}$ additions on the stability and epitaxy of $\mathrm{NiSi}_{2}$ films on (111) $\mathrm{Si}$, Journal of Applied Physics 84 (1998) 2583-2590.

[16] D. Mangelinck, J. Dai, J. Pan, S. Lahiri, Enhancement of thermal stability of NiSi films on (100) Si and (111) Si by Pt addition, Applied Physics Letters 75 (12) (1999) 1736-1738.

[17] C. Detavernier, C. Lavoie, Influence of Pt addition on the texture of NiSi on Si (001), Applied Physics Letters 84 (18) (2004) 3549-3551.

[18] O. Cojocaru-Mirédin, D. Mangelinck, K. Hoummada, E. Cadel, D. Blavette, B. Deconihout, C. Perrin-Pellegrino, Snowplow effect and reactive diffusion in the Pt doped Ni-Si system, Scripta Materialia 57 (5) (2007) 373-376.

[19] F. Panciera, D. Mangelinck, K. Hoummada, M. Texier, M. Bertoglio, A. De Luca, M. Gregoire, M. Juhel, Direct epitaxial growth of $\theta-\mathrm{Ni}_{2} \mathrm{Si}$ by reaction of a thin Ni (10at.\% Pt) film with Si (100) substrate, Scripta Materialia 78 (2014) 9-12.

[20] C. Mocuta, M. Richard, J. Fouet, S. Stanescu, A. Barbier, C. Guichet, O. Thomas, S. Hustache, A. Zozulya, D. Thiaudiere, Fast pole figure acquisition using area detectors at the DiffAbs beamline-Synchrotron SOLEIL, Journal of Applied Crystallography 46 (6) (2013) 1842-1853.

[21] P. Pangaud, S. Basolo, N. Boudet, J.-F. Berar, B. Chantepie, P. Delpierre, B. Dinkespiler, S. Hustache, M. Menouni, C. Morel, XPAD3: A new photon counting chip for X-ray CT-scanner, Nuclear Instruments and Methods in Physics Research Section A: Accelerators, Spectrometers, Detectors and Associated Equipment 571 (1) (2007) 321-324.

[22] P. Pangaud, S. Basolo, N. Boudet, J.-F. Berar, B. Chantepie, J.-C. Clemens, P. Delpierre, B. Dinkespiler, K. Medjoubi, S. Hustache, et al., XPAD3-S: A fast hybrid pixel readout chip for X-ray synchrotron facilities, 
Nuclear Instruments and Methods in Physics Research Section A: Accelerators, Spectrometers, Detectors and Associated Equipment 591 (1) (2008) $159-162$.

[23] K. Medjoubi, T. Bucaille, S. Hustache, J.-F. Bérar, N. Boudet, J.-C. Clemens, P. Delpierre, B. Dinkespiler, Detective quantum efficiency, modulation transfer function and energy resolution comparison between CdTe and silicon sensors bump-bonded to XPAD3S, Journal of Synchrotron Radiation 17 (4) (2010) 486-495.

[24] K. Medjoubi, A. Thompson, J.-F. Bérar, J.-C. Clemens, P. Delpierre, P. Da Silva, B. Dinkespiler, R. Fourme, P. Gourhant, B. Guimaraes, et al., Energy resolution of the CdTe-XPAD detector: calibration and potential for Laue diffraction measurements on protein crystals, Journal of Synchrotron Radiation 19 (3) (2012) 323-331.

[25] K. De Keyser, C. Detavernier, Gustav: Ghent University Software for Texture Analysis and Visualisation, http://www.cocoon.ugent.be/content/ gustav/

[26] E. Verleysen, Chemical analysis of thin films in electronic devices by analytical transmission electron microscopy methodologies, Ph.D. thesis, KU Leuven (2013).

[27] K. De Keyser, C. Van Bockstael, C. Detavernier, R. Van Meirhaeghe, J. Jordan-Sweet, C. Lavoie, Epitaxial formation of a metastable hexagonal nickel-silicide, Electrochemical and Solid-State Letters 11 (9) (2008) H266-H268.

[28] S. Gaudet, P. Desjardins, C. Lavoie, The thermally-induced reaction of thin Ni films with Si: Effect of the substrate orientation, Journal of Applied Physics 110 (11) (2011) 113524.

[29] F. Geenen, K. van Stiphout, M. Minjauw, J. Jordan-Sweet, A. Vantomme, 
C. Lavoie, C. Detavernier, The influence of $\mathrm{Al}$ alloying on nickel silicide formation and texture, to be submitted.

[30] K. Richter, H. Ipser, The Al-Ni-Si phase diagram between 0 and 33.3 at.\% Ni, Intermetallics 11 (2) (2003) 101-109.

[31] K. Richter, K. Chandrasekaran, H. Ipser, The Al-Ni-Si phase diagram. Part II: phase equilibria between 33.3 and 66.7 at.\% $\mathrm{Ni}$, Intermetallics $12(5)(2004) 545-554$.

[32] K. Chandrasekaran, K. Richter, H. Ipser, The Al-Ni-Si phase diagram Part III: Phase equilibria in the nickel rich part, Intermetallics 14 (5) (2006) 491-497.

[33] C. Detavernier, A. Ozcan, J. Jordan-Sweet, E. Stach, J. Tersoff, F. Ross, C. Lavoie, An off-normal fibre-like texture in thin films on single-crystal substrates, Nature 426 (6967) (2003) 641-645.

[34] D. Deduytsche, C. Detavernier, R. Van Meirhaeghe, C. Lavoie, Hightemperature degradation of NiSi films: Agglomeration versus $\mathrm{NiSi}_{2}$ nucleation, Journal of Applied Physics 98 (3) (2005) 033526.

[35] X. Gao, J. Andersson, T. Kubart, T. Nyberg, U. Smith, J. Lu, L. Hultman, A. J. Kellock, A. Zhang, C. Lavoie, et al., Epitaxy of ultrathin $\mathrm{NiSi}_{2}$ films with predetermined thickness, Electrochemical and Solid-State Letters 14 (7) (2011) H268-H270.

[36] Binary Alloy Phase Diagrams, ASM international, 1996.

[37] M. Ellner, S. Heinrich, M. Bhargava, K. Schubert, Einige strukturelle untersuchungen in der mischung nisi, Journal of the Less Common Metals 66 (2) (1979) 163-173.

[38] H. Von Känel, Growth and characterization of epitaxial Ni and Co silicides, Materials Science Reports 8 (5) (1992) 193-269. 
[39] J. Van Beek, P. Oberndorff, A. Kodentsov, F. Van Loo, Interactions in the Co-Ni-Si system at 800 C, Journal of Alloys and Compounds 297 (1) (2000) 137-143.

[40] F. Panciera, K. Hoummada, M. Gregoire, M. Juhel, D. Mangelinck, Pt redistribution in N-MOS transistors during Ni salicide process, Microelectronic Engineering 107 (2013) 173-177.

[41] A. Schrauwen, J. Demeulemeester, D. Deduytsche, W. Devulder, C. Detavernier, C. Comrie, K. Temst, A. Vantomme, Ternary silicide formation from Ni-Pt, Ni-Pd and Pt-Pd alloys on Si (100): Nucleation and solid solubility of the monosilicides, Acta Materialia 130 (2017) 19-27.

[42] F. d'Heurle, Nucleation of a new phase from the interaction of two adjacent phases: Some silicides, Journal of Materials Research 3 (01) (1988) 167195.

[43] M. E. Schlesinger, Thermodynamics of solid transition-metal silicides, Chemical Reviews 90 (4) (1990) 607-628.

[44] F. Geenen, W. Knaepen, F. Moens, L. Brondeel, A. Leenaers, S. Van den Berghe, C. Detavernier, Anisotropic thermal expansion of Ni, Pd and Pt germanides and silicides, Journal of Physics D: Applied Physics 49 (27) (2016) 275307.

[45] D. Smeets, A. Vantomme, K. De Keyser, C. Detavernier, C. Lavoie, The role of lattice mismatch and kinetics in texture development: $\mathrm{Co}_{1-x} \mathrm{Ni}_{x} \mathrm{Si}_{2}$ thin films on Si (100), Journal of Applied Physics 103 (6) (2008) 063506.

[46] V. Svilan, K. Rodbell, L. Clevenger, C. Cabral, R. Roy, C. Lavoie, J. Jordan-Sweet, J. Harper, Dependence of crystallographic texture of C54 $\mathrm{TiSi}_{2}$ on thickness and linewidth in submicron CMOS structures, in: MRS Proceedings, Vol. 427, Cambridge Univ Press, 1996, p. 53. 
[47] N. Breil, C. Lavoie, A. Ozcan, F. Baumann, N. Klymko, K. Nummy, B. Sun, J. Jordan-Sweet, J. Yu, F. Zhu, et al., Challenges of nickel silicidation in CMOS technologies, Microelectronic Engineering 137 (2015) 79-87.

[48] Q. Liu, G. Wang, N. Duan, H. Radamson, H. Liu, C. Zhao, J. Luo, Effects of carbon pre-germanidation implantation on the thermal stability of NiGe and dopant segregation on both n-and p-type ge substrate, ECS Journal of Solid State Science and Technology 4 (5) (2015) P119-P123.

[49] S. Shenouda, G. Molnar, G. Langer, G. Katona, F. Kristaly, D. Beke, 700 Kinetics of shift of individual interfaces in $\mathrm{Ni} / \mathrm{Si}$ system during low temperature reactions, Microelectronic Engineering 134 (2015) 14 - 21. doi:https://doi.org/10.1016/j.mee.2015.01.006. URL http://ww.sciencedirect.com/science/article/pii/ S0167931715000155

[50] L. Wieluński, D. Scott, M.-A. Nicolet, H. Von Seefeld, Alteration of Ni silicide formation by N implantation, Applied Physics Letters 38 (2) (1981) 106-108.

[51] A. Sharma, S. Mohan, S. Suwas, The influence of deposition temperature a on the structure, microstructure, morphology and magnetic properties of sputter deposited nickel thin films, Thin Solid Films 619 (2016) 91 - 101. doi:https://doi.org/10.1016/j.tsf.2016.10.024.

口 URL http://ww.sciencedirect.com/science/article/pii/ S0040609016306125

[52] G. Dalapati, C. Tan, S. Masudy-Panah, H. Tan, D. Chi, Low temperature grown highly texture aluminum alloyed iron silicide on silicon substrate for opto-electronic applications, Materials Letters 159 (2015) 455-458.

[53] M. Gregoire, R. Beneyton, P. Morin, Millisecond annealing for salicide formation: Challenges of NiSi agglomeration free process, in: Interconnect Technology Conference and 2011 Materials for Advanced Metallization (IITC/MAM), 2011 IEEE International, IEEE, 2011, pp. 1-3. 
[54] C. Feautrier, A. Ozcan, C. Lavoie, A. Valery, R. Beneyton, C. Borowiak, L. Clément, A. Pofelski, B. Salem, Impact of laser anneal on NiPt silicide texture and chemical composition, Journal of Applied Physics 121 (22) (2017) 225109. 